\title{
Determinants of Technology Commercialization Ecosystem for Universities in Kazakhstan
}

\author{
Gulnaz ALIBEKOVA ${ }^{1}$, Arsen TLEPPAYEV ${ }^{2}$, Tunc D. MEDENI ${ }^{3}$, Rashid RUZANOV ${ }^{4}$
}

Received: July 21, 2019 Revised: September 16, 2019 Accepted: September 24, 2019

\begin{abstract}
The purpose of this study is to identify the barriers of university and industry cooperation and to develop recommendations for the internal ecosystem of technology commercialization. The research method used is a survey of three categories of experts from 9 universities of Almaty (researchers, technology transfer managers, spin-off-owners). Despite the strong efforts of the government of Kazakhstan in building innovation infrastructure, there is a low level of innovation activity, less than $5 \%$ of university inventions are transferred into the industry. The results of the expert survey showed that the main barriers for cooperation between university and industry are: lack of resources to build university-industry links, lack of time due to high teaching load, poor qualification of technology transfer managers and lack of networking with industry. Based on the results of the expert survey, it is proposed to develop the ecosystem for the commercialization of university-based technologies, for which the following economic activities are important: human resources, financing, intellectual property management system, and intermediary infrastructure. The results of this study can be applied in developing the strategies and policies for universities, public research organizations, as well as for national $\mathrm{R} \& \mathrm{D}$ and higher education policies.
\end{abstract}

Keywords : Technology Commercialization, University Ecosystem, Economic Development, Entrepreneurial University, Technology Transfer Office, Kazakhstan

JEL Classification Code : $\mathrm{O} 31, \mathrm{O} 32$

\section{Introduction}

The transfer of scientific and technological knowledge from universities to industry is an absolute factor in the economic development of the country (Aghion, Dewatripont, \& Stein, 2008). The university should serve as a generator and conductor of knowledge, contributing to economic and social development through the triad of missions - education,

1 First Author and Corresponding Author, Ph.D., Institute of Economics, Al-Farabi Kazakh National University, Kazakhstan. [Postal Address: 29 Kurmangazy Street, Almaty, 050010, Kazakhstan] Email:galibekova77@gmail.com

2 Ph.D., Al-Farabi Kazakh National University, Kazakhstan.

3 Associate Professor, Ankara Yildirim Beyazit University, Ankara, Turkey.

4 Deputy Director, Institute of Economics, Al-Farabi Kazakh National University, Kazakhstan.

(c) Copyright: Korean Distribution Science Association (KODISA)

This is an Open Access article distributed under the terms of the Creative Commons Attribution Non-Commercial License (http://Creativecommons.org/licenses/by-nc/4.0/) which permits unrestricted noncommercial use, distribution, and reproduction in any medium, provided the original work is properly cited. research and entrepreneurship. The evolution of the mission and functions of universities in Western countries is due to two successive academic revolutions. In the United States in the 19th century, the first academic revolution led to the integration of research and teaching in universities. This system was progressive, since, firstly, the "cheap" labor force in the person of doctoral students reduced the costs of research, and, secondly, the constant generation of new ideas was ensured as an account of the continuous influx of new students to universities.

The merger between the academic sector and industry was the result of the second academic revolution, which developed step by step and ensured the successful commercialization of research results. At the first stage, the mechanism of intellectual property protection appeared, without plans on commercialization. The second stage is characterized by deep penetration of the concept of practical application of research results and, therefore, the academicians are involved in entrepreneurial activities and create innovative start-up companies. And, finally, at the 
third stage, scientific activity is fully aimed at generating income.

Analysis of the development of the university sector in Kazakhstan shows that, in accordance with this trend, over the last 8-10 years there is a gradual overflow of resources for research and development into the higher education sector. It is a positive trend because a lot of research support the conclusion about high correlation between higher education sector expenditures on R\&D and generating new technologies (Aruzhan, 2016).

However, as an element of the national system of commercialization of scientific research the universities of Kazakhstan have not yet properly developed in the field of technology commercialization. Meanwhile, domestic and foreign experts believe that the higher education system should and can perform the functions of a systemic coordinator for the innovative development of regions and play a leading role in effectively transition to a knowledgebased economy.

To direct domestic universities into the research mission, it is necessary to establish industry links, since the potential of research universities should be aimed at solving their problems. However, the universities and the industry have different perceptions and understanding of technology commercialization, which often leads to a lack of trust and communication problems throughout the innovation process.

The aim of the research is to reveal the differences in identification of university - industry collaboration and its barriers by face-to-face interviewing different groups of stakeholders: researchers, technology transfer office (TTO) managers and spin-off founders.

\section{Literature Review}

University technology commercialization issues are of high interest for scientists and policymakers. A bunch of the research reveals success factors of university technology transfer. Funding issues are the main subject of research in all countries for STI policy development. It is revealed that financial support of university-industry cooperation channels (building networks) is more important than financing the research itself, since research funding without support of university- industry cooperation does not lead to a greater likelihood of university patent licensing ( $\mathrm{Wu}$, Welch, \& Huang, 2015). Some scientists support this conclusion. University-industry links office and technology transfer office play the important role in university-industry cooperation development (Panagopoulos \& Carayannis, 2013). The links office should organize network events between scientists, venture capitalists, consultants and managers - all who can jointly provide human and financial resources for start-up companies. The main typical tasks for the TTO are: stimulating the disclosure of a potentially commercialized invention, managing intellectual property, searching for licensees and / or investors, providing resources for the development and operation of intellectual property, mediating between scientists, firms and the administration, developing effective policies and practices for the distribution of royalties, licensing, academic careers, and proactive inventions (Baldini, 2010; Panagopoulos \& Carayannis, 2013; Siegel, Veugelers, \& Wright, 2007).

Human capital is a strategic resource of the university. According to the World Bank, in transition countries only $16 \%$ of the level of economic growth depends on productive capital, and 64\% - on human capital. Development of human resources in the field of research should be based on the personal motivation of researchers. Personal characteristics of researchers have a stronger impact on the success of technology commercialization than the characteristics of their faculties and universities (D'Este \& Patel, 2007). In particular, the attitude of university scientists to the commercialization of research and development and their involvement in commercialization activities after disclosing an invention is much more important than TTO assistance (Lam, 2011).

Therefore, human capital development policy needs to take into account the following:

- in most cases, researchers choose the subject of study, based on personal values and attitude; the researcher autonomy helps to effectively build industrial communications and commercialize scientific knowledge. It is very difficult to involve researchers, especially fulltime one, in those studies in which they are not interested or feel they are not able to manage (Wu, 2007);

- full-time faculty is more inclined to cooperate than part-time one. In foreign practice, full-time researchers gain more significant social capital and wider professional contacts than part-time researchers (Bozeman \& Corley, 2004).

Human resource development suppose not only rational faculty management but technology transfer staff support as well. Some researchers argue that there is a need for internal incentives for scientists and departments to develop links between the university and industry (Jacobson, Butterill, \& Goering, 2004; Sá, Li, \& Faubert, 2011). It is important to encourage scientists for cooperation in the licensing of technologies, scientists' international mobility, knowledge and technology transfer activity (Siegel, Wright, \& Lockett, 2007; Edler, Fier, \& Grimpe, 2011; Kireyeva, Mussabalina, $\&$ Tolysbaev, 2018). Another powerful incentive is the fair distribution of intellectual property rights to the R\&D results, as well as fair remuneration of authors and investors for technology commercialization. Highly-qualified and experienced TTO managers, support by the university administration, researcher autonomy allows to prevent formal or symbolic perception of the commercialization norms and provides universities the opportunity to effectively establish industry links and commercialize their research and developments (Wu, 2007).

Another bunch of research is dedicated to the university technology transfer barriers. Many scientists point to a lack of time for research (Mosey, Lockett, \& Westhead, 2006; 
Gilsing, Bekkers, Bodas-Freitas, \& Van Der Steen, 2011). In addition, some university scientists may fear the loss of autonomy or independence in collaboration with firms (Tartari, Salter, \& D'Este, 2012). Also, the risk of information leakage to competitors is one of the main problems that prevents the private sector from cooperating with university scientists. (Bruneel, D'Este, \& Salter, 2010).

Low awareness and lack of contact are presented in the literature as likely obstacles (Kaufmann \& Tödtling, 2001; Muscio \& Pozzali, 2012). This problem is likely to be more significant if the industry and universities are little aware of the possibilities of cooperation (Galán-Muros \& Plewa, 2016). Weak recognition of the importance of universityindustry links is another obstacle to the transfer of technology from universities to industry. In addition, statefunded collaborative programs require university researchers to look for industry partners for application. Thus, the lack of relevant partners is a significant barrier (Belkhodja \& Landry, 2007).

Excessive theorization of knowledge for use in industry is another barrier (Ken, Chang, Chen, \& Weng, 2009). Many scientists also claim that their research is not related to the interests / needs of industry (Muscio \& Vallanti, 2014). In addition, some researchers cannot correctly assess their inventions and draw impracticable prospects for their technologies due to a insufficient understanding of market entry. Thus, unrealistic expectations about the value of their technologies make it difficult for university TTOs to sell inventions (Siegel, Waldman, Atwater, \& Link, 2004). In addition, university TTOs need to understand the needs of firms and the capabilities of technologies developed by university scientists to facilitate technology transfer between universities and industries. However, poor marketing / technical / negotiating skills of TTO specialists usually impede the development of the university-industry relationships (Owen-Smith \& Powell, 2001).

Another significant obstacle arises in transferring technology from universities to industry - cultural differences between academic institutions and enterprises. Some firms suppose that the scientific community cannot cooperate with industry due to differences in cultures. (Gilsing, Bekkers, Bodas-Freitas, \& Van Der Steen, 2011). Lack of entrepreneurship is a critical obstacle for academia to make connections between universities and industry (Ken, Chang, Chen, \& Weng, 2009). In addition, some studies suggest that university researchers and practitioners may not have a mutual understanding of expectations and working methods. (Muscio \& Vallanti, 2014). Although some firms seek to collaborate with universities, they may find that collaborating with research institutes and managing joint research projects can entail large costs, especially in terms of time and money. (Gilsing, Bekkers, Bodas-Freitas, \& Van Der Steen, 2011).

According to research, there are other institutional obstacles. The rules and regulations imposed by universities or government funding agencies are significant barriers (Hsu $\& \mathrm{Wu}, 2012$ ). Bureaucracy and inflexibility of university management is another barrier to the transfer of university technologies. (Brimble \& Doner, 2007; Styhre \& Lind, 2010). Styhre \& Lind (2010) showed that the university system is organized in a bureaucratic way, characterized by a functional organization of faculties, schools, departments and research groups, and a hierarchical order both in the structure of the university and including executive level (Shen, 2017)

The lack of financial resources to substantiate the concept or attract experienced technology transfer staff to the university is another critical obstacle for university scientists. For university scientists who are mainly engaged in basic research, additional funding is required to proof the concept of their inventions (Sá, Li, \& Faubert, 2011). Meanwhile, for university TTOs, hiring professionals with sufficient marketing skills, technical skills, and bargaining is expensive. Some studies have shown that the lack of venture capital is a critical barrier to technology transfer, especially since venture capitalists can assess the commercial potential of research and development results and ensure the development of university spin-of companies in various markets (Belkhodja \& Landry, 2007). University spin-offs are one of the key mechanisms for technology transfer (O'Shea, Allen, \& Chevalier, 2005). The main role of venture capitalists is to promote the formation of spin-off university companies, as they provide them with substantial risk capital, and to assist new firms (O'Shea, Allen, \& Chevalier, 2005). Inadequate reward for researchers is one of the obstacles mentioned in several studies (Belkhodja \& Landry, 2007). Without adequate remuneration, university researchers can publish their research in peer-reviewed journals and participate in prestigious conferences, but will not commercialize their developments (Shen, 2017).

It is obvious, that to be the recommended policy most efficient the universities should have the academic freedom. It enables establishment and enhancement of entrepreneurial culture at the university. A study of successful European universities revealed that entrepreneurial culture is a key element for transferring university technologies to the industry.

\section{Methodology}

Different methods are used by researchers to reveal university-industry bridging barriers by large-scale survey (Bruneel, D'Este, \& Salter, 2010). Vanderford and Marcinkowski (2015) used a face-to-face interview after online survey. A multiple-case study approach, involving the collection and analysis of qualitative data is another method (Meijer, Huijben, Boxstael, \& Romme, 2019).

In our research and administrative staff of eight technical (Satpayev Kazakh National Technical University, KazakhBritish Technical University, Kazakh Agrarian University, Al-Farabi Kazakh National University, Kazakh Leading Academy of Architecture and Construction, Almaty University of Technologies, Almaty University of Energy 
and Communications, Tynyshpayev Kazakh Academy of Transport and Communications) and one Medical University (Asfendiyarov Kazakh National Medical University) in Almaty was face-to face interviewed.

The number of interviewees is 47 people, of which 17 are research workers, 15 are managers of innovation and technology commercialization departments, and 15 are startup-owners.

Only three questions were interviewed. The questions were validated by conducting a sample survey.

The first question is designed to identify the differences between the three groups of respondents in the understanding of technology commercialization issues.

The sample survey allowed to design the survey questions as follows:

Question No. 1 "What do you understand by technology commercialization": rights)

1 Sale of technology (alienation of intellectual commercialization

3 Contracts for the production of goods by using the new technology

4 Contracts for technology development

Question No. 2 "Which channels are important for establishing links with industry?"

1 Personal relation

2 TTO

3 Conferences, meetings, exhibitions, etc

Question No. 3 "What are the problems of establishing industry links?"

Lack of incentives for researchers

The formal approach to the entrepreneurial mission
Inventors overvalue their inventions

Different university and industry norms and values university aim

Establishing links with industry is not the

Bureaucracy and inflexibility of administration

Lack of incentives for TTO managers

Lack of knowledge in technology commercialization

The closeness of industrial enterprises

High teaching load

Insufficient resources (financial, intellectual)

\section{Results}

Statistical testing of the significance of research results on the first question by using the z-criterion to estimate the difference between the two fractions of a sign has shown that there are no statistically significant differences in signs $(+/-)$ between the groups of researchers and founders $\left(\mathrm{Z}_{12}=-\right.$ $1,4, Z_{23}=0,99$ ) (Table 1). Therefore, it can be stated that, in general, these two groups are virtually unanimous in their opinion regarding the essence of technology commercialization (since the null hypothesis (H0) is not rejected by any of these answers to this question).

According to the Figure 1, it is clear that researchers would at the very least like to commercialize the technology by selling it, while the majority of TTO managers (65\%) view commercialization as a " sale of technology (alienation of intellectual rights)" (Figure 1).

Based on this, it can be stated that all groups are virtually unanimous in their opinion regarding the essence of technology commercialization (since the null hypothesis (H0) is not rejected by any of these answers to this question).

Table 1: Distribution of answers to Question 1

\begin{tabular}{|c|c|c|c|c|c|c|}
\hline Responses & $\begin{array}{l}\text { Researchers } \\
\text { (1) }\end{array}$ & $\begin{array}{l}\text { TTO managers } \\
\text { (2) }\end{array}$ & $\begin{array}{l}\text { Founders } \\
\text { (3) }\end{array}$ & $\mathbf{Z}_{12}$ & $\mathbf{Z}_{23}$ & $\mathbf{Z}_{13}$ \\
\hline Sale of technology (alienation of intellectual rights) & 0,4 & 0,65 & 0,4 & $-1,4$ & 0,99 & 0 \\
\hline Receiving grants on technology commercialization & 0,53 & 0,48 & 0,4 & 0,35 & 0,28 & 0,52 \\
\hline Contracts for the production of goods by using my technology & 0,6 & 0,48 & 0,6 & 0,73 & $-0,51$ & 0 \\
\hline Contracts for technology development & 0,6 & 0,48 & 0,2 & 0,73 & 1,08 & 1,55 \\
\hline
\end{tabular}




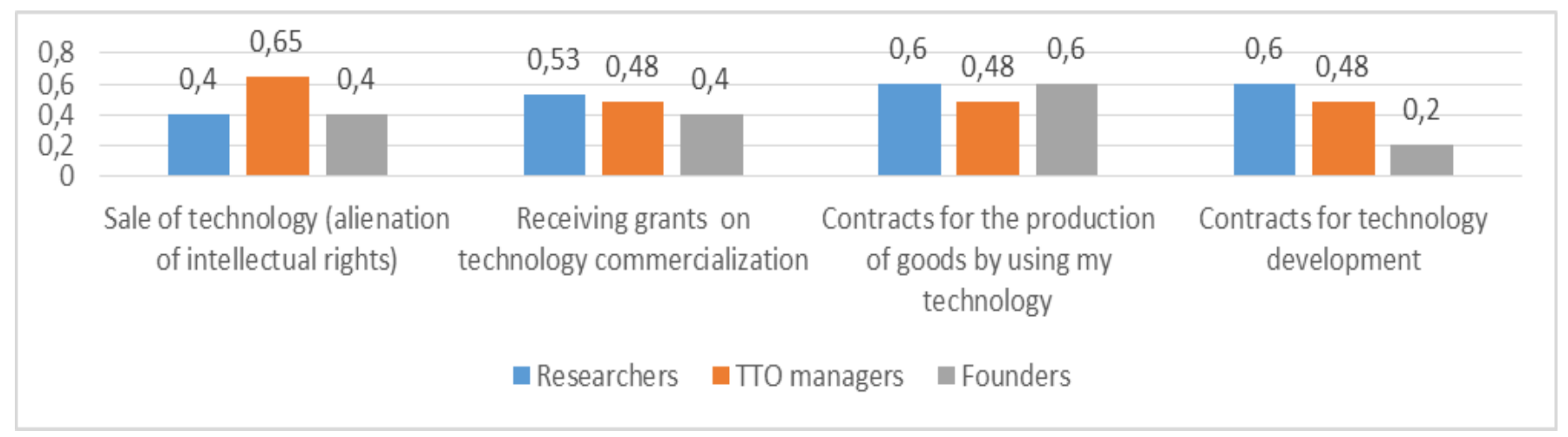

Figure 1: Distribution of answers to Question No. 1

The second question was compiled realizing that the main challenge in the commercialization of research results by universities is the weak industry links (Table 2). The sample survey shows that the main channels of communication between industry and universities come from personal relations, TTO and different events in science and technology. The purpose of the question is to assess the role of those channels (Figure 2).

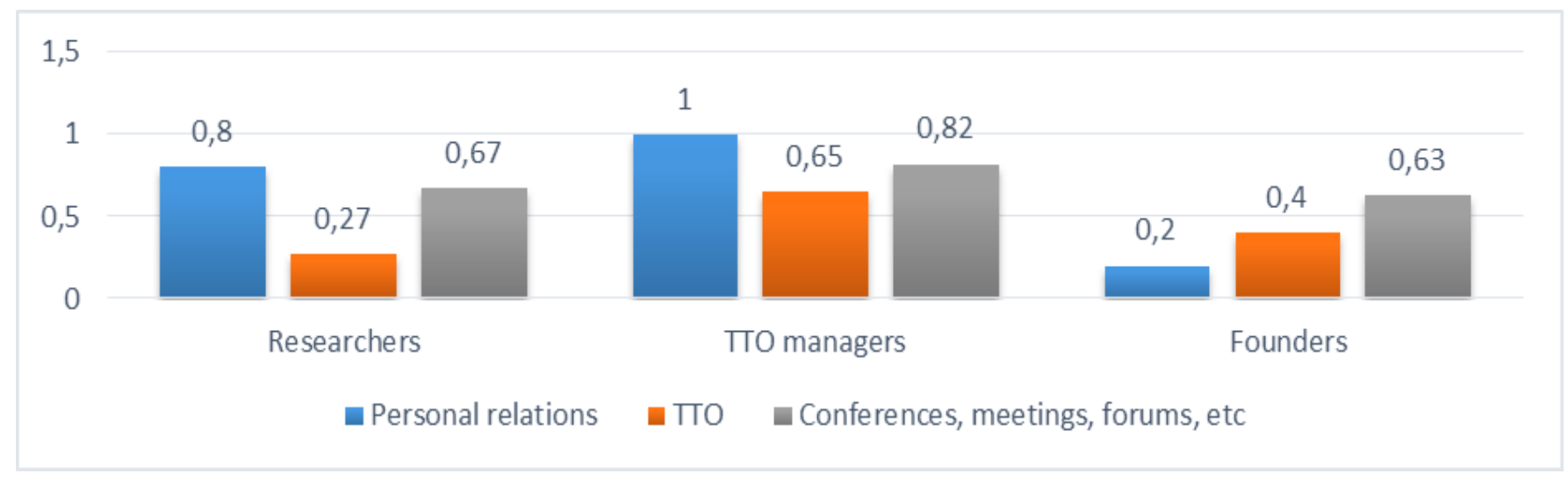

Figure 2: Distribution of answers to Question No. 2

The calculation of the Z-criteria on this question shows that almost no group of respondents considers TTO as a channel for establishing links with production. Most of the researchers and managers of these commercialization offices believe that the main channels are personal relations, whereas for founders of university spin-of companies to establish industry links, personal relations are the least important. This is confirmed by the fact that $\mathrm{Z} 23=4.08$ and $\mathrm{Z13}=2.43$ are higher than the upper critical value of the standardized normal distribution (1.96) at a significance level of 0.05 , and, therefore, the null hypothesis of equal shares of signs is rejected. The researchers, less than all other groups, consider the TTO as a channel for establishing industry links $(\mathrm{Z} 12=2.15)$ (Table 2$)$. All three groups of respondents believe that channels such as "conferences, exhibitions and meetings" are the most useful for the development of the industry links.

Table 2: Distribution of answers to Question 2

\begin{tabular}{|l|l|l|l|l|l|l|}
\hline & Researchers (1) & $\begin{array}{l}\text { TTO managers } \\
(\mathbf{2})\end{array}$ & $\begin{array}{l}\text { Founders } \\
(\mathbf{3})\end{array}$ & $\mathbf{Z}_{\mathbf{1 2}}$ & $\mathbf{Z}_{\mathbf{2 3}}$ & $\mathbf{Z}_{\mathbf{1 3}}$ \\
\hline Personal relations & 0,8 & 1,0 & 0,2 & 1,94 & 4,08 & 2,43 \\
\hline TTO & 0,27 & 0,65 & 0,4 & 2,15 & 0,98 & 0,56 \\
\hline Conferences, meetings, forums, etc & 0,67 & 0,82 & 0,63 & 1,02 & 1,05 & 0,27 \\
\hline
\end{tabular}

Answers to this question indicate that TTO are the least focused on communicating with industry and marketing new technologies. In fact, this is the case, since TTO in Kazakhstan deal only with consultations on the applications for innovative grants. The main issue, definitely, is identifying barriers of development with science-industry links (Figure 3). 


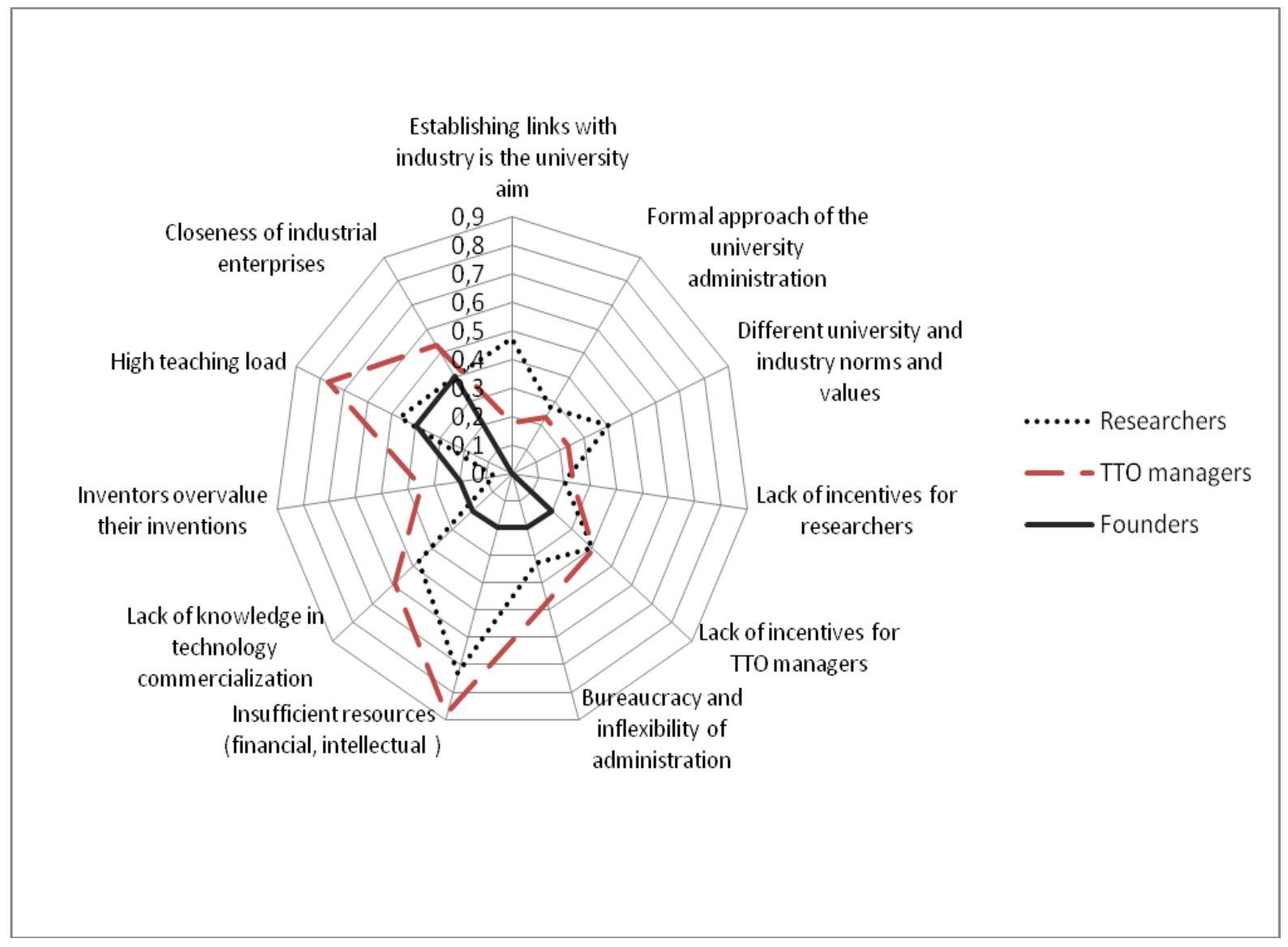

Figure 3: Distribution of answers to Question No 3

The identified problems of university and industry cooperation are mostly related to internal factors that the university administration is able to address independently in terms of clear understanding of the research or entrepreneurial mission. For example, both researchers and managers of technology transfer offices, first, identify such barrier as "lack of resources". The same categories of respondents indicate "the lack of time for networking because of high teaching load" on the second place. This issue comes from insufficient attention of the university management to the entrepreneurial mission. High teaching load is due to the desire of the university administration to provide a sufficient number of "full-time" teachers to keep the educational programs licensed. This effort lead to the "multi-profile" faculty. Multi-profile faculty is a factor of the devaluation of human capabilities. Studies show that professors of multi-profile courses consider this as a barrier to the development of university's research / entrepreneurial mission (Philpott, Dooley, O'Reilly, \& Lupton, 2011).

Along with high loads of teaching, interviewed experts are dissatisfied with the "low qualification of the technology transfer offices" and the issue of "establishing relations with industry is not a priority of the university". Technology transfer managers also indicate this barrier. It is on the 3rd place in the list of all designated barriers. Slightly lower ranked barrier is closeness of industry enterprises due to lack of resources to adjust those new technologies and small internal market (Table 3).

In general, the share of positive answers of all groups of respondents is almost the same, except for the response of founders about the lack of resources: the share of their positive answers differs significantly from the share of answers of the other two categories of respondents $(\mathrm{Z} 23=$ $3.01, \mathrm{Z} 13=2.1)$. Almost all identified problems can be eliminated by the university itself by developing required internal factors - financial, human, organizational etc. 
Table 3: Distribution of answers to Question 3

\begin{tabular}{|c|c|c|c|c|c|c|}
\hline 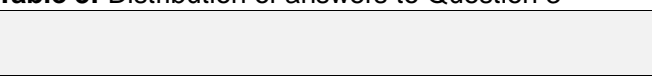 & $\begin{array}{l}\text { Researchers } \\
\text { (1) }\end{array}$ & $\begin{array}{l}\text { TTO managers } \\
\text { (2) }\end{array}$ & $\begin{array}{l}\text { Founders } \\
\text { (3) }\end{array}$ & $\mathrm{Z}_{12}$ & $Z_{23}$ & $\mathrm{Z}_{13}$ \\
\hline Establishing industry links is not the university aim & 0,47 & 0,176 & 0 & 1,77 & 1,01 & 1,89 \\
\hline Formal approach to the entrepreneurial mission & 0,27 & 0,235 & 0 & 0,20 & 1,2 & 1,29 \\
\hline Different university and industry norms & 0,4 & 0,235 & 0 & 1,0 & 1,2 & 1,69 \\
\hline Lack of incentives for TTO managers & 0,4 & 0,41 & 0,2 & 0,07 & 0,86 & 0,81 \\
\hline Bureaucracy and inflexibility of administration & 0,33 & 0,47 & 0,2 & 0,79 & 1,08 & 0,56 \\
\hline Insufficient resources (financial, intellectual) & 0,73 & 0,88 & 0,2 & 1,08 & 3,01 & 2,1 \\
\hline High teaching load & 0,47 & 0,765 & 0,4 & 1,37 & 1,54 & 0,52 \\
\hline Closeness of industrial enterprises & 0.4 & 0.53 & 0.4 & 0,73 & 0,51 & 0 \\
\hline
\end{tabular}

Based on the results of the expert survey, the following factors for the technology commercialization ecosystem are proposed: human resources management system and intellectual property management system, supported by funding mechanisms. For example, the highest technology transfer barrier which gained $60 \%$ of all responses by all groups of respondents refers to "Insufficient resources" (Figure 4).

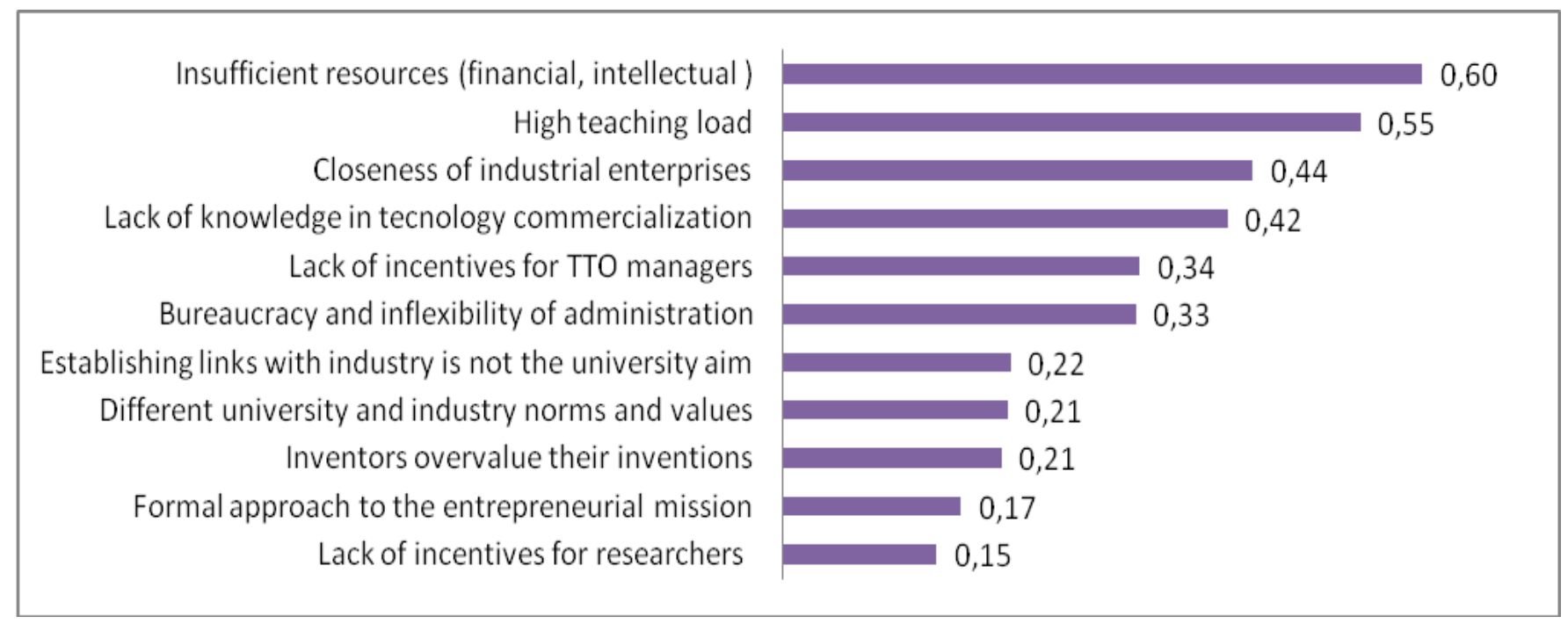

Figure 4: Total distribution of answers to Question No 3

By this respondents mean lack of financial (for organizing technology transfer events, travelling to industrial plants, participating at the international conferences and exhibitions, making field experiments, IP protection, consulting services, etc.) and intellectual or human capital (knowledge, skills, qualification) resources.

As we see from Figure 4, the next barrier to technology transfer is high teaching load. This can be result of weak and unbalanced human resource management. But the development of human resources in R\&D sector should be carried out taking into account the personal motivation of researchers. Moreover, the individual characteristics of researchers have a stronger influence on the success of technology commercialization than the characteristics of their faculties and universities and institutional factors.

\section{Conclusion}

Creating a technology commercialization ecosystem takes several years at the university, as it requires infrastructural and cultural changes to achieve success. The proposed recommendations on building the technology transfer ecosystem will be efficient in terms of the university's commitment to the entrepreneurial mission by stressing efforts on developing human capital and financial support of intellectual property management system of the university. Universities have to focus on enhancing the human capital in certain fields of knowledge and on joint efforts to transfer technology through cooperation. Motivational policies should provide attractive rewards to scientists for developing new applicable technologies. It is recommended to revise the instructions for recruitment and promotion of the regular staff to stimulate and reward for the dissemination of knowledge and technology, and thus 
strengthen the transfer of technology.

Universities need to increase their research budgets in order to strengthen their industry links, patent portfolios and turn research results into sound prototypes. Financial support of the development of university-industry channels of cooperation (networking) is more important than financing the research itself. Strengthening the university industry network can serve as a sound approach to attracting industry or government funding.

The universities should develop and implement their IP management system, which should optimize the transfer and commercialization of developed technologies. Without an effective intellectual property management system in universities and research organizations, it is impossible to establish an effective partnership with industry and ensure the practical implementation of scientific developments and technologies at enterprises in the real sector of the economy.

An important role is played by the liaison department, which creates opportunities for networking. The liaison department should organize networks between scientists, venture capitalists, consultants and managers who together provide the start-up company with human and financial resources.

\section{References}

Aghion, P., Dewatripont, M., \& Stein, J. (2008). Academic freedom, private sector focus, and the process of innovation. RAND Journal of Economics, 39(3), 617635.

Aruzhan, S., Farida, A., Alibekova, G., Tleppayev, A., \& Medeni, T. (2016). Econometric evidence of the effectiveness of different R\&D funding sources. International Journal of Economic Perspectives, 10(4), 317-330.

Baldini, N. (2010). Do royalties really foster university patenting activity? An answer from Italy. Technovation, 30(2), 109-116.

Belkhodja, O., \& Landry, R. (2007). The triple-helix collaboration: Why do researchers collaborate with industry and the government? What are the factors that influence the perceived barriers? Scientometrics, 70(2), 301-332.

Bozeman, B., \& Corley, E. (2004). Scientists' collaboration strategies: Implications for scientific and technical human capital. Research Policy, 33(4), 599-616.

Brimble, P., \& Doner, R. F. (2007). University-industry linkages and economic development: The case of Thailand. World Development, 35(6), 1021-1036.

Bruneel, J., D'Este, P., \& Salter, A. (2010). Investigating the factors that diminish the barriers to university-industry collaboration. Research Policy, 39(7), 858-868.

D’Este, P., \& Patel, P. (2007). University-industry linkages in the UK: What are the factors underlying the variety of interactions with industry? Research Policy, 36(9), 12951313.
Edler, J, Fier, H., \& Grimpe, C. (2011). International scientist mobility and the locus of knowledge and technology transfer. Research Policy, 40(6), 791-805.

Galán-Muros, V., \& Plewa, C. (2016). What drives and inhibits university-business cooperation in Europe? A comprehensive assessment. R\&D Management, 46(2), 369-382.

Gilsing, V., Bekkers, R. Bodas-Freitas, I. M., \& van der Steen, M. (2011). Differences in technology transfer between science-based and development-based industries: Transfer mechanisms and barriers. Technovation, 31(12), 638-647.

Hsu, S. L., \& Wu, C. T. (2012). Impacts of "Science and Technology Basic Act" on national universities in Taiwan. Technology Law Review, 9 (1), 151-204.

Jacobson, N., Butterill, D., \& Goering, P. (2004). Organizational factors that influence university-based researchers' engagement in knowledge transfer activities. Science Communication, 25(3), 246-259.

Kaufmann, A., \& Tödtling, F. (2001). Science-industry interaction in the process of innovation: The importance of boundary-crossing between systems. Research Policy, 30(5), 791-804.

Ken, Y., Chang, Y. H., Chen, Y. S., \& Weng, S. Y. (2009). The overall investigation of the development of academic institutions' technology transfers in Taiwan. Commerce \& Management Quarterly, 10, 625-646.

Kireyeva, A. A, Mussabalina, D. S., \& Tolysbaev, B. S. (2018). Assessment and identification of the possibility for creating IT clusters in Kazakhstan regions. Economy of Region, 14(2), 463-473.

Lam, A. (2011). What motivates academic scientists to engage in research commercialization: 'Gold', 'ribbon' or 'puzzle'? Research Policy, 40(10), 1354-1368.

Meijer, L. L. J., Huijben, J. C. C. M., van Boxstael, A., \& Romme, A. G. L. (2019). Barriers and drivers for technology commercialization by SMEs in the Dutch sustainable energy sector. Renewable and Sustainable Energy Reviews, 112, 114-126.

Mosey, S., Lockett, A., \& Westhead, P. (2006). Creating network bridges for university technology transfer: The Medici fellowship programme. Technology Analysis and Strategic Management, 18(1), 71-91.

Muscio, A., \& Pozzali, A. (2012). The effects of cultural distance in university-industry collaborations: Some evidence from Italian universities. Journal of Technology Transfer, 38(4), 486-508.

Muscio, A., \& Vallanti, G. (2014). Perceived obstacles to university-industry collaboration: Results from a qualitative survey of Italian academic departments. Industry and Innovation, 21(5), 410-429.

O'Shea, R., Allen, T., \& Chevalier, A. (2005). Entrepreneurial orientation, technology transfer, and spin-off performance of US universities. Research Policy, 34(7), 994-1009.

Owen-Smith, J., \& Powell, W. W. (2001). To patent or not: Faculty decisions and institutional success at technology 
transfer. Journal of Technology Transfer, 26(1-2), 99114.

Panagopoulos, A., \& Carayannis, E. (2013). A policy for enhancing the disclosure of university faculty invention, Journal of Technology Transfer, 38(3), 341-34.

Philpott, K., Dooley, L., O'Reilly, C., \& Lupton, G. (2011). The entrepreneurial university: Examining the underlying academic tensions, Technovation, 31(4), 161170.

Plewa, C. (2010). Key drivers of university-industry relationships-and the impact of organizational culture difference. Riga, Latvia: VDM Verlage Dr. Müller.

Sá, C. M., Li, S. X., \& Faubert, B. (2011). Faculties of education and institutional strategies for knowledge mobilization: An exploratory study. Higher Education, 61(5), 501-512.

Shen, Y.-C. (2017). Identifying the key barriers and their interrelationships impeding the university technology transfer in Taiwan: A multi-stakeholder perspective. Quality \& Quantity, 51(6), 2865-2884.

Siegel, D. S., Veugelers, R., \& Wright, M. (2007). Technology transfer offices and commercialization of university intellectual property: Performance and policy implications, Oxford Review of Economic Policy, 23(4), 640-660.

Siegel, D. S., Wright, M., \& Lockett, A. (2007). The rise of entrepreneurial activity at universities: Organizational and societal implications. , 16(4), 489-504.

Siegel, D. S., Waldman, D. A., Atwater, L. E., \& Link, A. N. (2004). Toward a model of the effective transfer of scientific knowledge from academicians to practitioners: Qualitative evidence from the commercialization of university technologies. Journal of Engineering and Technology Management, 21(1-2), 115-142.

Styhre, A., \& Lind, F. (2010). The softening bureaucracy: accommodating new research opportunities in the entrepreneurial university. Scandinavian Journal of Management, 26(2), 107-120.

Tartari, V., Salter, A., \& D'Este, P. (2012). Crossing the Rubicon: Exploring the factors that shape academics' perceptions of the barriers to working with industry. Cambridge Journal of Economics, 36(3), 655-677.

Vanderford, N. L., \& Marcinkowski, E. (2015). A case study of the impediments to the commercialization of research at the University of Kentucky. F1000Research, 4, 133.

$\mathrm{Wu}, \mathrm{W}$. (2007). Cultivating research universities and industrial linkages in China: The case of Shanghai. World Development, 35(6), 1075-1093.

Wu, Y., Welch, E., \& Huang W-H. (2015). Commercialization of university inventions: Individual and institutional factors affecting licensing of university patents. Technovation, 36, 12-25. 